https://doi.org/10.48009/3_iis_2020_83-94

Issues in Information Systems

Volume 21, Issue 3, pp. 83-94, 2020

\title{
AN INNOVATIVE BRIDGE COURSE TO ENHANCE RETENTION IN ENGINEERING PROGRAMS
}

\author{
George Stefanek, Purdue University Northwest, stefanek@pnw.edu \\ Niranjan Desai, Purdue University Northwest, desai39@pnw.edu \\ Thomas Brady, Purdue University Northwest, tbradyir@pnw.edu \\ Joseph Guncheon, Purdue University Northwest, iquncheo@pnw.edu
}

\begin{abstract}
This paper describes a freshman-year two-semester bridge course implemented in the engineering program of a teaching-focused university. The goal of the bridge course was to prepare new undergraduate engineering students in their first-year in order to help them successfully complete their technical degree, thereby improving retention in the engineering program. The engineering program was comprised of many students from underrepresented groups that were inadequately prepared to progress in an engineering program. In addition to innovative techniques described in this paper, the bridge course also incorporated several techniques recommended by research in engineering education, such as bringing freshmen students up to speed with mathematics and physics, providing freshmen with the supportive environment needed to transition successfully from high school to college, incorporating hands-on experiential learning techniques in the classroom, and using technology in the classroom. Results showed an average $84.6 \%$ sophomore-year retention rate in the engineering program in which the bridge course was implemented. Feedback from the dean of the engineering college and senior faculty members revealed that once students successfully transitioned from their sophomore to junior year, they went on to graduate. Finally, all students that were surveyed, without exception, felt that the bridge course was of benefit.
\end{abstract}

Keywords: Bridge Course, Engineering Education, Retention Engineering Education, STEM Education, STEM

\section{INTRODUCTION}

The United States requires qualified engineers and technologists. Acquiring higher education degrees has been positively correlated to economic growth and prosperity (Santiago \& Hensel, 2012). Attrition in engineering programs is a well-known issue (Santiago \& Hensel, 2012; Krause, Middleton \& Judson, 2015; James, 2007; Seymour \& Hewitt, 1997; Seymour, 2002; Crosling, Heagney \& Thomas, 2009; Ohland et. al, 2012; Ohland, Zhang, Thorndyke \& Anderson, 2004; Santiago, 2013; Desai \& Stefanek, 2017). Reports from US universities state that student retention rates in engineering lie in the range of $40-60 \%$ and that students that have the ability to complete an engineering degree are changing from engineering programs to pursue non-engineering majors (Santiago \& Hensel, 2012). In computing programs a drop rate from $30-40 \%$ (Beaubouef, J. \& Mason, J., 2005) is also common at many institutions.

Several studies have been conducted to obtain an understanding of the reasons for students transferring out of engineering programs (Seymour, 2002; Crosling, Heagney \& Thomas, 2009; Pascarella \& Terenzini, 1980). Seymour and Hewitt concluded that students transferred out of these programs because of their inability to cope with conceptual and financial problems (Seymour, Hewitt \& Friend, 1997). Other studies concluded that teaching techniques and pedagogy contributed to student lack of understanding of material being taught and constitute a reason for students transferring out of engineering programs (Seymour, Hewitt \& Friend, 1997; Santiago \& Hensel, 2012). Furthermore, students' lack of identification with their field of study also results in them discontinuing their degree program (Santiago \& Hensel, 2012; Crosling, Heagney \& Thomas, 2009).

Students feel pressure while transitioning from high school to university because this interferes with their family relationships, while simultaneously requiring them to independently manage their time and resources and meet deadlines (Santiago \& Hensel, 2012). It has been suggested that this stress is a factor that contributes to students' decision to leave engineering programs. Hence, several first-year engineering programs provide academic and social 
support systems to assist students in coping with this transition. It has still been observed that students transfer out of engineering programs due to a lack of interest in their chosen discipline (Santiago \& Hensel, 2012).

"Literature has identified math and physics aptitude as predictors of academic success in college" (Pembridge \& Verleger, 2013). Another reason attributed to the transfer of students specifically out of engineering programs is the difficulty that they have in succeeding with calculus. Despite there being tutoring services and review sessions available, an inability to succeed in math (specifically, calculus) has been observed to be a consistent obstacle to student retention in engineering programs. This issue is not unique to only one institution but is a ubiquitous problem (Van Dyken, Benson \& Gerard, 2015; Bischof, Zwolfer \& Rubesa, 2015; Hensel \& Hamrick, 2012).

Based on the above discussion, it can be seen that student attrition in engineering programs is a significant issue. To address the issue of decreasing retention rates, a mandatory two-semester "bridge course" offered in the freshman year of the engineering program at Purdue University North Central (currently Purdue University Northwest) was implemented, titled "Engineering Fundamentals".

This innovative "Bridge Course" was a two-semester course (Engineering Fundamentals 1 and 2) that assisted freshman-year students to make a transition to the academic rigor of an engineering program. The course was designed to meet the unique needs of students in the local community in which the incoming freshmen were found to be inadequately prepared to enroll in the core math and physics courses that are mandatory requirements of an engineering program. By making this course available, it permitted these students to complete their degree programs and pursue careers in engineering that they would otherwise be unable to pursue. Even though this paper focuses on a twosemester bridge course specifically setup for engineering programs, offering a bridge course or courses tailored to specific technology disciplines that can draw from the lessons learned from the courses described here may also help in retaining students in specific technology disciplines where retention is a problem.

\section{BACKGROUND}

Shadaram and Agrawal (Shadaram, Morrow \& Agrawal, 2012) describe the use of an engineering education improvement plan at University of Texas, San Antonio which included a fusion of strategies with a bridge program focused on creating a "just-in-time" (JIT) pedagogical approach for non-calculus ready students to increase the numbers, retention, and graduation time and rates of minority engineering students. The plan involved combining five education best practices of recruitment, formal mentoring via peer mentors, summer camp/engineering math preparatory workshops, academic year stipends, and summer internships at local and regional companies. The Just in Time Math (JITM) strategy was implemented to increase interaction between freshmen and engineering faculty and peers during the first semesters. As a result, more engineering students have shown more enthusiasm regarding the field of engineering resulting in better retention and graduation rates. The JITM course included lecture, lab and recitation components and a hands-on approach. These included traditional physics, engineering mechanics, electric circuits and computer programming courses. It replaced traditional math prerequisite requirements for the core courses so that students can advance in the engineering curriculum without first completing the required calculus sequence. This shifted the traditional emphasis on math prerequisite requirements to an emphasis on engineering motivation for math, with a "just-in-time" structuring of the new math sequence.

Lockwood-Cooke (Lockwood-Cooke, Davis \& Hunt, 2011) describe the creation of engineering learning communities at West Texas A\&M University that dual enroll first-year engineering students into a section of Fundamentals of Engineering and a freshman level mathematics course. This model integrated the curriculum of mathematics and engineering, and through Problem-Based Learning (PBL) provided real-world application to students. The goal of this program was to increase first-year engineering retention by creating a community-based environment and demonstrate applications of mathematics and physics into practical engineering problems using PBL to increase student engagement. Notably, there was an increase in the successful completion rate for Calculus I when compared to previous courses with the same instructor. Additionally, there was an increase in class attendance. Results indicated 
improved student performance in gateway mathematics courses based on historical data and improved persistence over students not enrolled in the learning community.

Erickson-Ludwig (Erickson-Ludwig \& Clyne, 2015) describe a summer bridge program oriented toward women and minority students entering engineering at the College of Engineering at Drexel University to help ensure academic success and retention. The College of Engineering hosted a "pre-orientation" program that familiarized students with the engineering curriculum and prepared them to succeed in their freshman year through community building and social activities. Program participants showed significant positive outcomes in areas such as problem solving and experimentation, communication, data interpretation and organizational skills. The participant retention was significantly higher than students that did not participate in the program. The program included students studying math, chemistry, and physics needed for success in college engineering. Students attended evening recitation sections to receive extra help with problem sets, and during the daytime participated in hands-on design and computer labs to familiarize them with relevant computer software. Projects included building solar cars and programming Lego NXT robots that competed in a Sumobot challenge. In the evenings and during the weekend, students socialized outside the classroom with Drexel Engineering faculty and students to build a community.

Dominguez (Dominguez, Zavala \& Alanis, 2013) introduced an integrated course of Physics and Mathematics for first-year engineering students at a large private university in northern Mexico with good results. The goals of the project were to a) help students make connections between physics and mathematics, b) increase students' motivation to advance in their engineering studies, and c) develop diverse competencies, such as critical thinking and the ability to do collaborative work. The program included the redesign of course content through the integration of physics and mathematics, teaching strategies, classroom environment, technology, and evaluation. This bridge course involved a cohort of students that took introductory math classes alongside their regular classes and received extra exercises with the assistance from faculty mentors and peers. Different supporting services were also incorporated into the program, providing students with individual guidance and advice from other program staff. The students received a personalized academic plan and class schedules for each semester to attain their degree on time. To motivate students, industry experts made presentations describing engineering career opportunities and personal experiences. Participating students outperformed others in summer and higher level math courses.

As with engineering program drop rates, computer science related programs can also average $30-40 \%$ in many institutions (Beaubouef \& Mason, 2005) therefore making these programs possible candidates for bridge programs. Some schools try various techniques to improve retention from group-based projects, pair programming, problembased learning, specialized labs, but not in the form of a bridge course. Unlike semester long bridge courses in engineering programs, extensive bridge courses appear to be uncommon in undergraduate computer related programs. However, bridge programs are fairly common for Master of Science in Computer Science or Computer Information Technology for those individuals seeking to get a Master's degree in the field without having a computing undergraduate degree.

Purdue University Computer Science Bridge Program (Purdue University, 2020) offers undergraduate students with a high potential for Computer Science and Data Science, but lacking programming experience a two-week program where students live on campus and develop a network of peers vital to their academic success. The Bridge Program introduces students to basic computer science and programming concepts at a comfortable pace. Topics covered via lecture and lab include Java Basics, Input and Output, Primitive Types, Selection and Repetition, Arrays, Graphical User Interfaces, Methods and Classes, Inheritance and Exceptions, Dynamic Data Structures, and Interfaces. At the end of the program there is a live coding exam to simulate what the exams will be like in the CS courses.

Huangs (Huangs, Clark, Clements \& Janzen, 2012) describes an undergraduate bridge computer science course (CS0) enabling students to choose from robotics, gaming, music, and mobile apps areas. This allows students to learn basic programming, teamwork, and college-level study in an area of personal interest. The course uses Project-based 
Learning (PBL) approaches as well as a focus on both academic and non-academic factors shown to increase student retention. There was increased student retention and academic performance post CS0 courses.

Pomalaza-Ráez \& Groff (Pomalaza-Ráez \& Groff, 2003) describe a freshman bridge course at Indiana UniversityPurdue University Fort Wayne called ETCS 101-Introduction to Engineering, Technology, and Computer Science. This course attempts to increase retention by providing students with computer and personal development skills, by including projects that utilize hardware and software, Internet and Web software tools, and team-teaching. The main project of the course has small teams of students design, build, program, and test an autonomous mobile robot using LEGO ${ }^{\circledR}$ parts, sensors, and the Robotic Command eXplorer (RCX) controller.

\section{STATEMENT OF THE PROBLEM}

Student attrition in engineering programs is a significant issue. The engineering program at PNC was comprised of many students from underrepresented groups that were not adequately prepared to progress in an engineering program. To address the issue of decreasing retention rates, a mandatory two-semester "bridge course" was implemented in the freshman year at PNC in order to improve retention in the engineering program.

\section{SIGNIFICANCE OF THE STUDY}

Based upon the background search, there already exist numerous bridge courses that have been implemented in the freshman year at universities in various parts of the United States. The common theme between these courses is:

1) Bringing freshmen up to speed with mathematics and physics to perform well in an engineering program.

2) Providing freshmen with the social support networks needed to transition from high school to college.

3) Incorporating experiential learning techniques to solve hands-on engineering design problems.

4) Using technology into the classroom to retain student interest and expose them to contemporary technologies.

The bridge courses described in this paper is unique in the following ways:

1) It incorporates all the above features into one consolidated course that spans the entire freshman year.

2) The entering engineering freshmen at PNC were not required to fulfill any additional admission criteria outside the general university requirements (high school GPS of 2.0). Since PNC was a land-grant university at a regional campus comprised of a significant number of students from underrepresented groups, its goal was to serve the community and provide all students in the area with the opportunity to obtain a college education. Students with academic abilities that ranged from low-to-high could pursue their college education. Since the engineering school didn't have any additional criteria for entrance, the engineering program often had students that were highly unprepared to face the academic rigor of a college level engineering plan of study. Additionally, a large number of students at the school were first-generation college students and came from financially disadvantaged backgrounds.

3) The bridge courses were developed to ensure that the engineering department graduated a specified number of students from the local community and fit the profile described above, thereby growing the program.

Despite being intended for students from a weaker academic background, the two-semester bridge course provided all students with a solid foundation that covered rigorous technical material relevant to an engineering curriculum. The foundation laid by these fundamentals courses opened the field of engineering up to students that would normally not consider engineering. The efficacy of the courses was further demonstrated by the fact that students were able to successfully transfer to engineering from different unrelated programs such as nursing and the liberal arts. These students completed their engineering degree in the same amount of time as the other students.

\section{METHODOLOGY}

Data collected by the Dean of the College of Engineering and Technology at PNC represented the total number of students that enrolled in the mechanical, electrical and civil engineering programs in the college over a period of eight 
years from 2008 - 2016. The data was collected on a total population of 374 incoming freshman engineering students over the 2008 to 2016 period. Student retention data was collected for the second semester freshman year in the second bridge course (ENGR 181), and from required engineering courses in the sophomore year (ME 270 and ECE 201), junior year (ME 302 and ECE 301), and senior year (ECE 311 and ENG 461).

The engineering programs were introduced into PNC in fall 2007, after which the engineering fundamentals twosemester bridge courses were introduced into the curriculum in the fall of 2008. Subsequently, in the fall of 2016, PNC merged with another regional campus within the Purdue University system and a unified curriculum was incorporated into the unified university which is not identical to that which was in existence at PNC. Hence, student retention data pertaining to the engineering fundamentals bridge courses are only available from the time that it was implemented between 2008 and 2016.

\section{OVERVIEW OF THE BRIDGE COURSES}

The engineering fundamentals courses (the bridge courses) at PNC served to prepare incoming students for future engineering courses. The primary goal was retention of students in the engineering program. To meet this goal, the course material presented was designed to be directly relevant to courses taken by the students in their following years. The bridge courses which were offered during the first two semesters in the freshman year were not oriented toward design engineering; but focused on strengthening the students' fundamentals of mathematics, physics and problem solving as applied to engineering. A strong emphasis was placed on both mathematics as well as physics, unlike some bridge courses which focus only on mathematics.

The mathematics and basic science parts of the courses were presented using fundamental engineering concepts to give students a better understanding of the concept. One example is the use of electrical waveforms to demonstrate the physical meaning of differentiation and integration. Students were first introduced to the definitions and units of charge, current, voltage, energy, and power. At the same time using the associated units, relationships were developed between units through calculus. When circuit elements-resistors, capacitors, and inductors-were introduced, these concepts were used to solve problems. Additionally, mathematics and physics concepts were taught by both mathematics and physics professors, as well as engineering professors. The purpose of doing this is to impart the knowledge to students both from the perspective of a mathematician/physicist, as well as an engineer.

The course lectures included a short active learning element that could be used by both instructor and the students to assess how well the material was being learned. In addition to the standard lecture format, the course included a learning lab to reinforce concepts covered in lecture. The lab involved students working on hands-on problems. In the lab sections, the class size was smaller than the lecture which allowed for the delivery of the material that was adjusted based on evaluation of student performance. During the last 10 minutes of each lab, an in-class quiz was given. The quizzes which made up $20 \%$ of the final course grade were based on material covered earlier in the lab. The quizzes were designed by the lab instructor to evaluate the student's understanding of the concepts that have been presented in lecture and reinforced during the lab.

The lab instructor was typically an engineering student in their junior or senior year that had taken the courses which provided benefits in that the instructor could directly relate to how students benefitted from the courses. Having an instructor that is closer in age and educational background to the students also may increase the likelihood that students will ask for assistance during the lab period. Throughout the course, students are encouraged to first seek help from their peers and from study groups when having difficulties, and then ask instructors for help.

Throughout the course, the importance of teamwork was stressed. A common activity in the learning lab was for students to work out problems in small groups which allowed them to help each other under the supervision of a lab instructor. The composition of the groups was chosen by the lab instructor to ensure that each group has a mix of academically stronger and weaker students. This balance allowed for enhanced peer learning. Group membership was changed based on the type of problem being solved. 
The use of instructor supervised peer learning allowed for students to share their approach to a problem. During the course, multiple approaches to solving the same type of problem were presented. For instance, students tended to gravitate toward a single method to solve most circuit problems. However, when students that used different methods were placed in the same group, they could share their solution with the group.

Lab projects were designed to be relevant to later classes such as circuits, fluid mechanics, and heat transfer. Each lab project had the class divided into small structured groups (3-4 students) with a designated leader. The leader was responsible for ensuring that everyone participated in the work. For this to be effective, the project leader submitted a performance review of each of the group members which was reflected in the participation grade assigned for the project. Group leaders were rotated for each project to ensure that every member had an opportunity to lead the group.

The use of lab projects that were spread across engineering areas (mechanical, civil, and electrical) served to expose students that were undecided which area of engineering to pursue. The lab projects also promoted interdisciplinary work in the student groups. All incoming engineering students were required to take the fundamentals courses regardless of the branch of engineering that they would be studying. As a direct result of this early exposure to real problems from all the engineering areas, some students changed which engineering field they would study. Students were also exposed to basic programming using MATLAB and the $\mathrm{C}++$ programming language.

Finally, since these were new courses in a newly developed engineering program that did not have a rigid structure, faculty had the flexibility to modify the courses in accordance with students' needs. Feedback obtained from students and instructors in advanced courses allowed for new/additional material to be covered in the bridge courses.

\section{Course Structure}

This section contains a description of the bridge (engineering fundamentals) courses - ENGR 171 and ENGR 181.

\section{ENGR 171 Course}

Module 1: Covers course philosophy and advice on how to be a successful student.

Module 2: Covers fundamental mathematical concepts of inequalities, intervals, sets, boundaries, absolute value properties, increments, in-plane distances, properties and slopes of lines, definition of trig functions, coordinate systems, trig identities, and conversion between coordinate systems. There is an in-class active learning exercise given to the students relating to coordinate system conversion. To aid in visualization, physical objects inside the classroom are used to demonstrate projections into planes.

Module 3: Units of basic electrical circuits are covered: coulombs, amperes, volts, watts, and AC voltage waveforms. The in-class active learning element is a problem involving basic circuit units and determining properties of a voltage waveform including changing the amplitude, frequency, and phase shift.

Module 4: Electrical components are introduced, starting with resistors, capacitors, and inductors. The physical operation of resistors is briefly covered before Ohm's law is introduced followed by derivatives and integrals. The example problems deal with voltage/current waveforms through a capacitor/inductor.

Exam 1: Week six starts with the first exam. During the following class period, the graded exams are returned to the students. Students who scored below a 70 on the exam are told to show up to the lab section at the normal time for a review of the exam questions. Students are strongly encouraged to seek help if there is a topic they are struggling with, as all the exams are comprehensive.

Module 5: Independent and dependent voltage and current sources are introduced with examples of single element single loop circuits followed by parallel and series circuit reduction methods, voltage and current division rules, transistors, and differential equations. Kirchhoff's laws are introduced allowing for more complex circuits to be analyzed. The use of matrix math for solving system of equations is also introduced using Excel and MATLAB. An in-class active learning element involves a simple followed by extensive circuit reduction problems.

Exam 2: Week ten begins with a review for the upcoming test later that week. The exams in the fundamentals bridge courses are all comprehensive: each exam will have at least one problem based on earlier material. 
Module 6: Graded exams are returned and the same procedure as for the first exam is followed. Vectors, rigid body statics, dot and cross product, and the linear spring model are covered in this module. When demonstrating vector addition/subtraction, graphical methods are used to aid in visualization. When dealing with 3-D systems, physical objects in the classroom are used to aid with the visualization of vectors and their angles.

Final Exam: A review for the final exam is followed later in the week by the exam which is comprehensive.

\section{ENGR 181 Course}

Module 7: Contains a concise review of the material covered in the previous semester over a period of two weeks. The module begins by repeating the advice on how to be a successful student.

Module 8: Moments with a discussion of units and the torque/power relationship are introduced. There are several example problems that are worked out to demonstrate the calculation of moments. There are in-class active learning elements for the calculation of the determinant of a matrix, calculation of a moment about a specific axis, and replacement of a loading system with an equivalent force and moment.

Module 9: Distributed loads and centroids are introduced. There is an in-class active learning element involving a beam with a simple distributed load. Several simple shapes are used as examples for the calculation of centroids.

Exam 1: The first exam is administered during the next lecture period.

Module 10: Nodal and loop analysis is introduced followed by operational amplifiers (op-amps) and second order differential equations. Several example circuits are solved step by step using nodal analysis. There is an in-class active learning element involving finding the nodal equations and voltages for a basic circuit. The need for second order differential equations is established by the analysis of a circuit containing a resistor, capacitor, and inductor.

Module 11: Number systems and logic gates are covered. The module starts with a breakdown of the standard base 10 decimal system, before demonstrating the binary system. The process for converting between binary and decimal is presented followed by octal and hexadecimal systems. Finally logic gates and truth tables are covered.

Exam 2: The second exam is administered during the first lecture period of week thirteen.

Module 12: The definitions for the components of complex numbers are presented along with the complex representations of sine and cosine, phasors, impedance, and matrix operations. There is an in-class active learning element involving converting complex numbers between coordinate systems. There is an in-class active learning element involving an AC circuit.

Final Exam: The final exam is administered during the seventeenth week.

\section{RESULTS}

Table 1 contains data that was collected by the Dean of the College of Engineering and Technology at PNC and presents the total number of students that enrolled in the engineering programs in the college (mechanical, electrical, and civil engineering) over a period of 8 years from 2008 - 2016. The engineering programs were introduced into PNC in Fall 2007, after which the engineering fundamentals bridge courses were introduced into the curriculum in the fall of 2008 to assist the underprepared students from the local community in order to not withdraw from their chosen degrees. Subsequently, in the fall of 2016, PNC merged with another regional campus within the Purdue University system and a unified curriculum was incorporated into the unified university which is not identical to that which was in existence at PNC. Hence, student retention data pertaining to the engineering fundamentals bridge courses are only available, and presented in this table, from the time that it was implemented with the content identical to that described in this paper. 
Table 1. Student Retention Data

\begin{tabular}{|c|c|c|c|c|c|c|c|c|c|c|c|}
\hline \multirow{2}{*}{$\begin{array}{l}\text { Academic } \\
\text { Year }\end{array}$} & \multicolumn{2}{|c|}{ Freshman } & \multicolumn{2}{|c|}{ Sophomore } & \multirow{3}{*}{$\begin{array}{c}\text { Spring } \\
\text { Avg }\end{array}$} & \multirow{3}{*}{$\begin{array}{c}\text { Sophomore } \\
\text { Year } \\
\text { Retention } \\
\%\end{array}$} & \multicolumn{2}{|c|}{ Junior } & \multicolumn{3}{|c|}{ Senior } \\
\hline & $\begin{array}{l}\text { Fall } \\
\text { EN } \\
\text { GR } \\
171\end{array}$ & $\begin{array}{c}\text { Spring } \\
\text { ENGR } \\
181\end{array}$ & $\begin{array}{l}\text { ME } \\
270\end{array}$ & $\begin{array}{c}\text { ECE } \\
201\end{array}$ & & & $\begin{array}{l}\text { ME } \\
302\end{array}$ & $\begin{array}{c}\text { ECE } \\
301\end{array}$ & $\begin{array}{l}\text { ME } \\
316\end{array}$ & $\begin{array}{c}\text { ECE } \\
311\end{array}$ & $\begin{array}{c}\text { ENG } \\
461\end{array}$ \\
\hline $2008-2009$ & 37 & 18 & & & & & & & & & \\
\hline $2009-2010$ & 32 & 24 & 12 & 13 & 12.5 & 33.8 & & & & & \\
\hline $2010-2011$ & 48 & 32 & 17 & 16 & 16.5 & 51.5 & 11 & & & & \\
\hline $2011-2012$ & 50 & 32 & 26 & 27 & 26.5 & 55.2 & 13 & & 12 & & 9 \\
\hline $2012-2013$ & 46 & 39 & 29 & 30 & 29.5 & 59 & 13 & 8 & 11 & 8 & 13 \\
\hline $2013-2014$ & 49 & 45 & 29 & 36 & 32.5 & 70.7 & 16 & 8 & 13 & & 11 \\
\hline $2014-2015$ & 47 & 32 & 38 & 37 & 37.5 & 76.5 & 13 & 10 & 17 & 7 & 21 \\
\hline $2015-2016$ & 65 & & 36 & 36 & 36 & 68.1 & 19 & 14 & 11 & 9 & 27 \\
\hline Average & & & & & & 59.25 & & & & & \\
\hline
\end{tabular}

The data began to be collected when the engineering program was initiated at PNC in the fall of 2008. Table 1 reads diagonally across. For example, for an academic year, say fall 2008, it starts with the incoming freshman students in fall 2008 and moves diagonally across presenting the number of these students that moved into their sophomore year courses, then into their junior year and finally into their senior year. Hence, 37 students entered the program in fall 2008 and 13 students graduated in 2012.

These retention percentages have been calculated as the ratio of the number of students entering the fall_semester of sophomore year's "gateway courses" and the number of students in the fall semester of freshman year. We chose this method of retention because, based upon consultation with the dean of the Department of Engineering and Technology at the time, his experience with the program was that if someone made it through freshman year and enrolled in sophomore year, it was almost certain that they would graduate at the end of 4 years with their engineering degree. For example, there were 50 students that enrolled in fall of academic year $2011-2012$ as freshman. Consequently, of these there were 29 students that enrolled in ME 270 and 30 students that enrolled in ECE 201 in fall of academic year 2012 - 2013 as sophomores. Hence, in computing the retention percentage for students transitioning from academic year 2011 - 2012 to 2012 - 2013, the ratio 29.5 / $50=0.59$ (59\%) was used as the retention percentage. Please note that the value 29.5 used in the calculation is an average of 29 and 30 students enrolled in the aforementioned courses in the fall semester of the sophomore year.

Another point to note: There were originally 47 students enrolled in the fall semester of freshman year in 2014 2015. Of these, 32 students moved on to the spring semester of the same year. Subsequently, in this cohort of students, there were 36 students in the fall semester of sophomore year of 2015 - 2016. These additional 4 students were transfer students, and including them in the retention calculation creates an inaccuracy. Hence, in calculating the retention percentage for this cohort, the ratio $32 / 47=68.1 \%$ has been used for this year.

\section{DISCUSSION AND ANALYSIS}

A more detailed analysis of Table 1 is now presented. It can be seen from the table that 37 new freshman students were enrolled in Engineering 171 during their first semester in the fall of 2008. Of these, 18 students successfully progressed to the sophomore year after clearing Engineering 181 in the spring semester of their freshman year. Of these students that entered their sophomore year, 12 were enrolled in Basic Mechanics 1: Statics (ME270) and 13 in Linear Circuit Analysis (ECE 201). Statics and Linear Circuit Analysis are core gateway course requirements for all civil, mechanical and electrical engineering students. Hence there was some overlap between students in these classes. Consequently, for the purpose of computation of the retention percentage an average value of these students in the Statics and Linear Circuit Analysis classes was computed and entered into the column having the header "Spring Average" in Table 1. Hence, the retention rate computed for the sophomore year was as follows: sophomore year retention percentage $=[(12.5 / 37) * 100]=33.8 \%$. The retention numbers were computed based upon the number of 
students in Statics and Linear Circuit Analysis because these are gateway courses to engineering in which students are exposed for the first time to critical thinking and solving abstract engineering problems. Performance in these courses is indicative of whether a student is likely to complete the engineering program and graduate or withdraw from the program. Subsequently, the number of students completing Thermodynamics (ME 302) and Signals and Systems (ECE 301) in their junior year, and Heat and Mass Transfer (ME316), Electric and Magnetic Fields (ECE 311), and Senior Design (ENG 461) in their senior year are presented in Table 1 since these are staple courses fundamental to the mechanical and electrical engineering disciplines offered in the junior and senior years. Eleven students completed Thermodynamics (ME 302) in their junior year, and none were enrolled in Signals and Systems (ECE 301) at that time. Finally, 12 students completed Heat and Mass Transfer (ME316) in their senior year and 9 completed their Senior Design Projects and graduated in spring 2012. Slight discrepancies in the numbers are due to students transferring into the program from other universities, or due to them withdrawing from courses and then repeating them again. Also, some students were majoring in mechanical engineering and earning a minor in electrical engineering, or vice versa, resulting in a possible overlap between the students in the junior and senior year courses shown in Table 1. The remainder of the table can be interpreted identically to that described above.

It can be seen from Table 1 that the retention percentage gradually improved after the first year that the engineering fundamentals bridge courses were introduced. The anomalous low retention percentage of $33.8 \%$ for the academic year 2008 - 2009 was most likely because this was the first year that the courses were introduced into the newly developed engineering school at PNC. As discussed earlier, the engineering fundamentals courses were dynamic courses that were modified each year by taking both student and faculty feedback (from faculty that taught students that completed these courses and were now in their sophomore year and beyond) into account. By incorporating these suggestions into the courses in subsequent years, they were improved, which is demonstrated by the increasing freshman retention rates.

Knight's (Knight, Carlson \& Sullivan, 2007) review of the literature for engineering retention found a study that analyzed data from 27,065 first-year students enrolled at 388 four-year colleges and universities between 1985 and 1990 that showed a $47 \%$ graduation rate. Review of the literature since by the same authors found an average graduation rate of 56\%. Our results show an average 59.25\% retention rate. Exact percentages of graduation rates are not available. However, feedback from the dean of the engineering college and from the department's senior-most professor both of whom developed the bridge courses described in this paper revealed that once students successfully transitioned from their sophomore to junior year, they went on to graduate.

\section{BRIDGE COURSE FOR COMPUTER SCIENCE PROGRAMS}

Since computer science, technology and computer information system programs often suffer from high attrition during the freshman year, introducing a bridge course(s) for these programs may be an option for some universities. Following a similar structure as in the engineering bridge course a bridge course for these computer science programs is proposed. A semester one course can be set up with modules starting with the first module focusing on philosophy, advice on how to be a successful student in computer science programs, and good learning techniques and problem solving. Module 2 would focus on fundamental mathematical concepts relevant to a particular computer program. For computer science programs calculus and discrete math might be covered whereas with computer information technology and computer information systems algebra, trigonometry, and discrete math. Module 3 might focus on web technologies, module 4 on programming, module 5 on database systems, module 6 on networking, module 7 on cybersecurity, module 8 on mobile technology and module 9 on cloud based computing, module 10 on artificial intelligence and deep learning, and module 11 on data science. As with the engineering bridge course, team-based exercises and projects would be used as well as team-based programming focusing on problem solving to real-world like problems. The use of robots, integrated development environments, and user-interface and user-experience techniques and technologies could be integrated into the modules. 


\section{CONCLUSIONS}

Attrition in engineering programs is a well-known issue. The approaches that have been implemented to address the retention issue in engineering programs can be generally categorized into common themes. Some approaches involve assisting students in improving their mathematics and physics skills and some involve the incorporation of hands-on projects in the freshman year. Additionally, some programs have strived to create a more collaborative, interactive and supportive learning environment in which students are more in contact with their peers and instructors and thereby do not feel isolated. Finally, incorporating the implementation of modern technological tools into the classroom to make the lectures more exciting and to keep pace with the increased influence of technology in students' lives has been found to be beneficial.

The two-semester bridge course described in this paper is unique since it incorporates all the above features into one consolidated course spanning the entire freshman year. The course was introduced into the engineering curriculum at Purdue North Central, a land-grant university whose goal was to provide all students in the area with the opportunity to obtain a college education. The academic environment in which this course has been implemented is unique since the entering engineering freshmen were selected based upon the same criteria as all other students admitted into the university. Since the engineering school didn't have any additional criteria for entrance, the engineering program often had students that were unprepared or under-prepared to face the academic rigor of a college level engineering plan of study. Also, PNC's student body comprised many underrepresented groups since several students were firstgeneration college students coming from financially disadvantaged backgrounds. Despite being bridge courses, Engineering Fundamentals 1 and 2 were not remedial courses and covered technical matter rigorously.

Review of the literature for engineering retention between 1985 and 1990 showed an approximate $47 \%$ graduation rate (Knight, Carlson \& Sullivan, 2007). Review of the literature after 1990 by the same authors found an average reported graduation rate of 56\%. Our results show an average 59.25\% retention rate in the engineering program at PNC in which the two-semester bridge course was implemented. Precise percentages of graduation rates are not available at PNC. However, feedback from the dean of the engineering college and senior faculty members revealed that once students successfully transitioned from their sophomore to junior year, they went on to graduate.

The efficacy of the courses was further demonstrated by the fact that students were able to successfully transfer into the engineering program from different unrelated programs such as nursing and the liberal arts. These students completed their engineering degree in the same amount of time as the other students. Finally, all students that were surveyed, without exception, felt that they got their money's worth out of the bridge course.

The integration of either a bridge course directly into the curriculum or prior to starting an engineering or technology program may be a good solution to increasing retention as this example engineering bridge course illustrates. In computing programs the drop rate from $30-40 \%$ (Beaubouef, J. \& Mason, J., 2005) is common at many institutions and may be good candidate programs for developing a bridge course to help students succeed in the computing disciplines as well. Using this bridge course as a model with content adapted to each particular technology discipline may help in improving retention rates of students in various technology programs as well.

\section{REFERENCES}

Beaubouef, J. \& Mason, J. (2005, June). Why the High Attrition Rate for Computer Science Students: Some Thoughts and Observations. Inroads - The SIGCSe Bulletin. 37(2).

Bischof, G., Zwolfer, A., \& Rubesa, D. (2015, June). Correlation between engineering students' performance in mathematics and academic success. In Proceedings of the 122nd ASEE Annual Conference and Exposition, Seattle, WA.

Crosling, G., Heagney, M., \& Thomas, L. (2009). Improving student retention in higher education: Improving teaching and learning. Australian Universities' Review, The, 51(2), 9. 
Desai, N., \& Stefanek, G. (2017, June). An Introductory Overview of Strategies Used to Reduce Attrition in Engineering Programs. In Proceedings of the 124th ASEE Annual Conference and Exposition, Columbus, $\mathrm{OH}$.

Desai, N., \& Stefanek, G. (2017, March). A literature review of the different approaches that have been implemented to increase retention in engineering programs across the United States. In Proceedings of the ASEE Zone 2 Conference, San Juan, Puerto Rico.

Erickson-Ludwig, A. \& Clyne, A. M. (2014, June). Summer Diversity Program enhances female and underrepresented minority student academic performance and retention in the Drexel University College of Engineering. In Proceedings of the $121^{\text {st }}$ ASEE Annual Conference \& Exposition, Indianapolis, IN.

Haungs, M., Clark, C., Clements, J., \& Janzen, D. (2012, February). Improving first-year success and retention through interest-based CSO courses. In Proceedings of the 43rd ACM technical symposium on Computer Science Education (pp. 589-594).

Knight, D. W., Carlson, L. E., \& Sullivan, J. F. (2007, June). Improving engineering student retention through handson, team based, first-year design projects. In Proceedings of the International Conference on Research in Engineering Education. Honolulu, HI.

Lockwood-Cooke, P. R., Davis, S. J. \& Hunt, E. M. (2011, June). Engineering Learning Communities: Relationships, Results, and Retention. In Proceedings of the $118^{\text {th }}$ ASEE Annual Conference \& Exposition, Vancouver, BC, Canada.

Melsa, J. L. (2007). Transforming engineering education through educational scholarship. Journal of Engineering Education, 96(3), 171-172.

Ohland, M. W., Sheppard, S. D., Lichtenstein, G., Eris, O., Chachra, D., \& Layton, R. A. (2008). Persistence, engagement, and migration in engineering programs. Journal of Engineering Education, 97(3), 259-278.

Ohland, M. W., Zhang, G., Thorndyke, B., \& Anderson, T. J. (2004, October). Grade-point average, changes of major, and majors selected by students leaving engineering. In Frontiers in Education, 2004. FIE 2004. 34th Annual (pp. T1G-12). IEEE.

Pascarella, E. T., \& Terenzini, P. T. (1980). Predicting freshman persistence and voluntary dropout decisions from a theoretical model. The Journal of Higher Education, 51(1), 60-75.

Pembridge, J., \& Verleger, M. (2013, June). First-Year Math and Physics Courses and their Role in Predicting Academic Success in Subsequent Courses. In Proceedings of the $120^{\text {th }}$ ASEE Annual Conference and Exposition, Atlanta, GA.

Pomalaza-Ráez, C., \& Groff, B. H. (2003). Retention 101: Where robots go... students follow. Journal of Engineering Education, 92(1), 85-90.

Purdue University. (2020). Computer Science Bridge Program. www.cs.purdue.edu/undergraduate/bridge/.

Santiago, L. \& Hensel, R. (2012, June). Engineering Attrition and University Retention. In Proceedings of the $119^{\text {th }}$ ASEE Annual Conference and Exposition, San Antonio, TX.

Santiago, L. (2013, June). Retention in a First Year Program: Factors Influencing Student Interest in Engineering. In Proceedings of the $120^{\text {th }}$ ASEE Annual Conference and Exposition, Atlanta, GA.

Seymour, E., Hewitt, N. M., \& Friend, C. M. (1997). Talking about leaving: Why undergraduates leave the sciences (Vol. 12). Boulder, CO: Westview press.

Seymour, E. (2002). Tracking the processes of change in US undergraduate education in science, mathematics, engineering, and technology. Science Education, 86(1), 79-105. 


\section{Issues in Information Systems}

Volume 21, Issue 3, pp. 83-94, 2020

Shadaram, M., Morrow, T. B. \& Agrawal, C. M. (2012, June). A Comprehensive Plan with Emphasis on Math Preparation to Improve Retention and Graduation Rates in Engineering Fields. In Proceedings of the ASEE Annual Conference \& Exposition, San Antonio, TX.

Van Dyken, J., Benson, L. \& Gerard, P. (2015, June). Persistence in Engineering: Does Initial Mathematics Course Matter? In Proceedings of the 122nd ASEE Annual Conference and Exposition, Seattle, WA. 